University of Nebraska - Lincoln

DigitalCommons@University of Nebraska - Lincoln

Agronomy \& Horticulture - Faculty Publications

Agronomy and Horticulture Department

2010

Crop Registration: The Pathway to Public Access of Plant Genetic Materials to Build Crops for the Future

D. D. Ellis

USDA, ARS, National Center for Genetic Resources Preservation

K. A. Garland-Campbell

USDA, ARS, Wheat Genetics, Quality Physiology and Disease Research, kim.garland-campbell@usda.gov

J. A. Grotenhuis

USDA, ARS, National Center for Genetic Resources Preservation

M. M. Jenderek

USDA, ARS, National Center for Genetic Resources Preservation

Jeffrey F. Pedersen

University of Nebraska-Lincoln, jpedersen1@unl.edu

Follow this and additional works at: https://digitalcommons.unl.edu/agronomyfacpub

Part of the Agricultural Science Commons, Agriculture Commons, Agronomy and Crop Sciences Commons, Botany Commons, Horticulture Commons, Other Plant Sciences Commons, and the Plant Biology Commons

Ellis, D. D.; Garland-Campbell, K. A.; Grotenhuis, J. A.; Jenderek, M. M.; and Pedersen, Jeffrey F., "Crop Registration: The Pathway to Public Access of Plant Genetic Materials to Build Crops for the Future" (2010). Agronomy \& Horticulture -- Faculty Publications. 937.

https://digitalcommons.unl.edu/agronomyfacpub/937

This Article is brought to you for free and open access by the Agronomy and Horticulture Department at DigitalCommons@University of Nebraska - Lincoln. It has been accepted for inclusion in Agronomy \& Horticulture -Faculty Publications by an authorized administrator of DigitalCommons@University of Nebraska - Lincoln. 


\title{
Crop Registration: The Pathway to Public Access of Plant Genetic Materials to Build Crops for the Future
}

\author{
D.D. Ellis,` K. A. Garland-Campbell, J. A. Grotenhuis, M. M. Jenderek and J. F. Pedersen
}

\begin{abstract}
Starting in 1926 and continuing for $80+y r, 11,241$ crop genetic materials have been registered as of 31 Dec. 2008. The crop registration process is an important pathway to publically describe and document new and useful genetic materials and to incorporate these into the public domain via the National Plant Germplasm System (NPGS). Crop Registration materials are now searchable via the Germplasm Resources Information Network (GRIN) and demand for registered materials remains strong with more than 9150 registered accessions distributed in the past 26 yr by the NPGS. Guidelines continue to evolve to accommodate global factors effecting germplasm exchange such as Intellectual Property Rights (IPR) and international treaties (i.e., The International Treaty on Genetic Resources for Food and Agriculture). Together with (i) the advent of the new Journal of Plant Registrations; (ii) the facilitated search capabilities of GRIN; (iii) the development and definition of genetic materials needing registration (cultivars, germplasm, genetic stocks, parental lines, and mapping populations); and (iv) the recognition and allowance of IPR rights: the registration of crops is a healthy viable dynamic registration system to meet the needs of breeders over the next $80 \mathrm{yr}$.
\end{abstract}

D.D. Ellis, J.A. Grotenhuis, and M.M. Jenderek, USDA, ARS, National Center for Genetic Resources Preservation, Fort Collins, CO, K.A. Garland-Campbell, USDA, ARS, Wheat Genetics, Quality Physiology and Disease Research, Pullman, WA, and J.F. Pedersen, USDA, ARS, Grain, Forage, and Bioenergy Research, Lincoln, NE. Mention of trade names or commercial products in this article is solely for the purpose of providing specific information and does not imply recommendation or endorsement by the U.S. Department of Agriculture. Received 8 Oct. 2009. *Corresponding author (david.ellis@ars.usda.gov).

Abbreviations: GRIN, Germplasm Resources Information Network; IPR, intellectual property rights; IT, The International Treaty on Plant Genetic Resources for Food and Agriculture; NCGRP, the National Center for Genetic Resources Preservation; NPGS, National Plant Germplasm System; PVP, Plant Variety Protection; SMTA, Standard Material Transfer Agreement

$\mathrm{R}$ egistration of crop genetic materials has provided breeders access to important germplasm for more than $80 \mathrm{yr}$ (since 1926). It also provided a means to publish, describe, and distribute these important materials, and also publically recognize breeders accomplishments. Crop registrations have been the underpinning for the public release of information about new cultivars, germplasm, genetic stocks, parental lines, and mapping populations (hereafter referred to as genetic materials) with traits of interest critical for improvement of crops to meet present and future demands for food security and productivity. At present, registration of genetic materials does not cover hybrids yet their parental lines qualify for registration and there are no regulations limiting the registration of genetic materials containing genetically modified traits.

Initiated as an idea for a few grain crops (wheat [Triticum aestivum L.], barley [Hordeum vulgare L.], and oat [Avena sativa L.]) to

Published in Crop Sci. 50:1151-1160 (2010).

doi: $10.2135 /$ cropsci2009.10.0585

Published online 21 May 2010.

(C) Crop Science Society of America | 5585 Guilford Rd., Madison, WI 53711 USA

All rights reserved. No part of this periodical may be reproduced or transmitted in any form or by any means, electronic or mechanical, including photocopying, recording, or any information storage and retrieval system, without permission in writing from the publisher. Permission for printing and for reprinting the material contained herein has been obtained by the publisher. 
provide the public release and documentation of elite cultivars, Crop Registration now includes the registration of crops in 122 genera. Starting in 1926 with the registration of 271 standard cultivars to which new improved cultivars could be compared, the number of registered genetic materials now exceeds 11,240. Although many of the fundamental guidelines used for the registrations of crops still exist today, a continuing rotation of committee members, evolving categories of registration materials and the publication of registration articles in four different journals over the last $80 \mathrm{yr}$ has resulted in difficulty researching registered genetic materials.

Registration of plant genetic materials offers breeders and developers the opportunity to (i) document their intellectual contributions in the development of these materials; (ii) publicize the advances made in specific crops; and (iii) obtain a peer reviewed paper for all their efforts. Traditionally, the peer reviewed manuscript, and hence the registration of genetic materials, has been more important to public sector researchers than researchers in the private sector. However, with added incentives in the public sector to protect intellectual property, it is likely that increasingly the public sector will follow the private sector in protecting developed materials through Plant Variety Protection or patents in conjunction with registration of the materials. To our knowledge, the registration of genetic materials by the Crop Science Society of America represents the only crop registration system of its kind in the world where detailed information of developed plant genetic materials are published in a peer-reviewed journal in conjunction with the deposition of the material in a federally run genebank. The registration of these materials is tied very closely to the requirement for public release of the registered materials. Registration of genetic materials by international scientists has always been strong with $14 \%$ of all registered materials coming from overseas. Our hope is that genetic materials developed throughout the world will see the benefits of registration and that international submissions will increase.

In this paper, we provide a history of Crop Registration and help unravel the challenges with the evolving management of registration articles and genetic materials. Also highlighted is the path by which voucher seed samples are handled and the relatively new guidelines for the registration of genetic material covered by intellectual property (i.e., patents and plant variety protection) as well as the registration of material covered by the International Treaty on Plant Genetic Resources for Food and Agriculture.

\section{METHODS}

The number of registration articles, number and categories of genetic materials registered, and background information on the development of the crop registration system was obtained from issues of the Journal of the American Society of Agronomy (1920-1960), Agronomy Journal (19491964), Crop Science (1961-2007) and the Journal of Plant
Registrations (2007-2008) both in hard copy and on-line. All on-line data was collected in March 2009.

The distribution and related information of registered genetic materials were obtained from GRIN. This network includes data on the number and category for all registered accessions (1926-2008) and distribution data of registered accessions since 1982 .

For the purpose of this paper, all analyses were done through 31 Dec. 2008.

\section{History of Crop Registration}

Ninety years ago (1919) in Chicago, IL, at the annual meeting of the American Society of Agronomy a Committee on Varietal Standardization was formed in recognition of the need to unify and clarify information from the growing number of varieties ${ }^{1}$ which were the foundation of cultivated crops (Oakley 1920). In 1922 this committee recommended the "development of a method of registration of varieties so that new and valuable stocks may be better known and made available to more investigators." (Agronomic Affairs, 1922). The Committee on Varietal Standardization set the stage for the handling of individual crops by committees of experts in those crops, a precursor to the organization of distinct Crop Subcommittees. At this 1922 meeting, it was suggested that the Committee draw up "detailed plans" for the registration of crop varieties. In 1923, the Committee on Methods of Registration of Varieties of Wheat, Oats and Barley was formalized and presented a plan for registrations to be "conducted in cooperation with the Bureau of Plant Industry of the United States Department of Agriculture through the Office of Cereal Investigations" under a memorandum of understanding between the American Society of Agronomy and the Bureau of Plant Industry (Agronomic Affairs, 1923).

Although only three crops were accepted for varietal classification by the Society (wheat, oats, barley) many of the guidelines used today for Crop Registration were outlined more than $85 \mathrm{yr}$ ago (Agronomic Affairs 1923). The 1923 plan included details such as:

1. Each registered variety shall have a registration number and name;

2. Committees shall consist of three persons appointed by the President of the American Society of Agronomy, terms shall be $3 \mathrm{yr}$ and one new committee member shall be appointed annually;

3. To qualify for registration, varieties must be tested in "replicated experiments at a Federal or State experiment station" over 3 to $5 \mathrm{yr}$ and must be significantly superior than the standard varieties in some attribute;

\footnotetext{
${ }^{1}$ Variety is defined as a taxonomic subdivision of a species which may be naturally occurring or may result from breeding. Use of "cultivar", defined as a cultivated variety, is more correct than use of "variety" to describe new genetic materials developed for cultivation. Use of "varietal" or "variety" in this article is limited to instances where it is necessary for historical correctness.
} 
4. The requestor must submit an Application for Registration and a sample of "not less than six heads and one ounce of seed" to the chairman of the respective committee;

5. The requestor shall be responsible for maintaining the registered material;

6. Approval of the registration application must be made by at least two members of the committee;

7. On approval the applicant will be notified of the registration number (a precursor to the registration certificate) and details of each registration will be published in the Journal of the American Society of Agronomy.

8. Seed and data will be forwarded to the Bureau of Plant Industry who shall "have custody of the samples" which "shall be available for inspection or study" (the earliest record we found of the U.S. Government having curatorial duties for voucher seed samples of registered material).

In 1924 the first Committees for Crop Registration were formed for wheat, oat, and barley; chaired by J. Allen Clark, T.R. Stanton, and H.V. Harlan, respectively (Agronomic Affairs, 1924a). At the annual meeting, the Committee on Varietal Standardization put forth a plan to adopt "special strains of known high performance ability" to be registered as standards in varietal trials (Agronomic Affairs, 1924b). This notion was refined in 1925 by the recommendation that all commercial varieties of these crops be registered (Agronomic Affairs, 1925). The 1925 annual report identified M.A. McCall of the office of Cereal Investigations as the appointee by the Bureau of Plant Industry as the officer in charge of registration. The committee closed their 1925 annual report confirming that registration would be based on merit and that if registration of wheat, oat, and barley "proves of value", then other crops may be registered in the future.

The first Crop Registrations were published in the October 1926 issue of the Journal of the American Society of Agronomy. Clark et al. (1926a) registered all 229 wheat varieties described in the Classification of American Wheat Varieties, U.S. Department of Agriculture Bulletin no. 1074. This article was followed by Clark et al. (1926b) for the registration of 23 improved wheat varieties. Stanton et al. (1926) registered 42 standard varieties of oat (described elsewhere) and 22 improved oat varieties. Harlan et al. (1926) registered three barley varieties. The initial registration articles for improved varieties of wheat and oat contained a descriptive paragraph followed by 4 to $5 \mathrm{yr}$ of data (yield and rust infection for wheat and yield only for oat) while barley registrations only contained a descriptive paragraph indicating that a tabulation of yields had been submitted with the registration application. Another interesting note is the mention that four barley varieties had been submitted for registration (Agronomic Affairs, 1926b), yet only three were approved highlighting that even in this first year, rigorous standards for defining, reviewing, and accepting materials for registration were applied to the granting of crop registrations.

Corn (maize) (Zea mays L.) was the next crop discussed for varietal registration status as noted in 1926 "that in the very near future a system of registration of selfed lines of corn which are used in hybrid combinations and of the hybrid combinations themselves will be desirable" Agronomic Affairs (1926a). However, in 1927 the subcommittee for corn registration felt there was no advantage to registering open-pollinated varieties of corn and that there were no selfed lines of merit or scientific interest (Agronomic Affairs, 1927). This continued through 1929 when a new subcommittee was appointed to establish guidelines for registration of corn varieties (Agronomic Affairs, 1929). Although the first applications for registration for corn were received in 1931 (Agronomic Affairs, 1931) the Committee on Varietal Standardization voted against the registration of corn in 1932 (Agronomic Affairs, 1932). Debate on the registration of corn continued for decades as evidenced by the 1956 annual report from the committee on Varietal Standardization and Registration where it stated "In view of divided opinions among corn breeders relative to advantages of registering inbred lines, the committee decided not to proceed with such registration" (Annual Meeting, 1956). It was not until almost $80 \mathrm{yr}$ after first discussed that a corn cultivar was registered ('Obatanpa GH', Badu-Apraku et al., 2006), although maize germplasm, as well as parental lines, were registered 35 yr earlier in 1971. Pea (Pisum sativum L.) is another crop that took four or more decades from the first submitted application for registration (Agronomic Affairs, 1931) to actually having a variety registered (Gritton and Hagedorn 1971).

Although corn was the first crop after oat, barley, and wheat to be discussed, other crops were more successful in getting varieties registered in a timely manner. Subcommittees for the registration of cotton (Gossypium hirsutum L.) and soybean [Glycine max (L.) Merr.] were set up in the spring of 1928 (Agronomic Affairs, 1928a, 1928b). Cotton initially faced opposition as the Committee felt that cotton needed to attain "practical homozygosity, by means of a system for controlled self-pollination" before consideration for registration. Despite this opposition the identification of standard cotton varieties was underway by 1934 (Agronomic Affairs, 1934) and the first registrations were allowed for cotton in 1936 (Brown 1936) and for soybean in 1943 (Morse, 1943). In 1929 variety registration of sorghum was first discussed with 73 standard varieties listed for registration in Agronomic Affairs (1936) and the first improved sorghum varieties were registered in 1938 (Parker, 1938). By the late 1930s, varietal registration of crops was well underway with additional consideration for rye (Secale cereale L.), flax (Linum usitatissimum L.), sweet clover (Trifolium spp.) and alfalfa (Medicago sativa L.). 
As stated, the registration of cultivars (varieties) began in 1926 starting with standard cultivars and then improved cultivars. In 1968 Registration articles were expanded to include "(1) lines released for the use as parents of hybrids and (2) elite germplasm released for breeding purposes" (Registration of Field-crop Cultivars, Parental Lines and Elite Germplasm. 1968. Crop Science 8(2):261-262). The first parental lines registered were for pearl millet [Pennisetum americanum (L.) Leeke] (Button 1969) and the first germplasm registered was in barley (Suneson 1969). Although a CSSA committee on Genetic Stocks was formed in 1966, the first registration of genetic stocks did not occur until 1990 with the registration of the soybean line T295H (Palmer and Skorupska 1990). Mapping populations were subsequently added as a separate category of genetic materials with the first being a soybean population, NC113 (Narvel et al., 2004).

Crop registrations were originally published in the American Journal of Agronomy until it changed its name to the Agronomy Journal in 1949. In 1961, the Crop Science journal was initiated to provide crop breeders and crop physiologists a venue to publish research articles specifically in their field and of interest to crop scientists (Johnson and Hamilton 1961, Johnson 1985). As the official journal for the Crop Science Society of America (CSSA), the journal Crop Science recognized the importance of improved or special materials resulting from the research of plant breeders (Hanway 1985) and therefore took over the publication of registration articles in 1962. In 2007, plant registrations moved from the journal Crop Science to its own journal, the Journal of Plant Registrations which allowed a more complete description of new plant material by encouraging a format parallel to "quality referred journal articles" (Pedersen 2007).

\section{Issues with Researching Registration Articles}

The publication of plant registrations in three different journals, over multiple decades, with no consistent format for location or timing was highlighted as a problem in 1963 by a CSSA Committee on Cooperation with Seed where it was stated that "The piecemeal publication of registration articles has resulted in a scattering of registration articles on a certain crop through some 30 yr." The report went on to say, "Information on specific cultivars requires extensive search of the literature as no lists of registration cultivars have been published". The committee recommended that "Alphabetical lists of registered cultivars should be published" (Annual Meeting, 1964).

Gathering information on the registration of specific crops is compounded by the fact that there has been relatively little consistency in when and where registration papers were placed in the journals. In 1926, the first registration articles were listed at the end of the "Articles" section in the table of contents (i.e., see Clark et al., 1926a). This became the general format, however inconsistencies in the treatment of registration articles continued and include:
- 1926-Omission of wheat CV 230 in the very first registration article (Clark et al., 1926a)

- 1927-There was no mention of Crop Registration articles in The Preparation of Manuscript for the Journal of the American Society of Agronomy (Suggestions by the Editors) (Agron. J. 1927, 19(1):67-71).

-1936-The 73 initial sorghum cultivars registered were never published as articles and were only listed in the minutes from the annual meeting with characteristics or other information published elsewhere (Agronomic Affairs, 1936);

- 1938-A sorghum registration paper was placed in the middle of the Articles section (Parker, 1938) instead of at the end as was customary;

- 1953-The Committee on Varietal Standardization and Registration recommended that registration articles be published once per year, preferably in November (Annual Meeting, 1953). This lasted $3 \mathrm{yr}$;

-1956-A registration paper was listed under the "Notes" section (Graber, 1956) rather than at the end of the article section which was the standard;

-1962-Crop Science initiated the inclusion of a category entitled "Registration of Crop Cultivars" in the table of contents to help identify when an issue contained registration articles yet in 1966, an oat registration article appeared without mention of a registration article in the table of contents (Jensen, 1966);

-2007, 2008-articles on the registration of a maize haploid mapping population and chickpea (Cicer arietinum L.) germplasm (Hussain et al. [2007] and Mahortra et al. [2008]) were listed under Genetic Stocks.

When Crop Science took over publication of registration articles, early attempts at clarity of registration materials were favorable. The trend was to publish each variety in individual papers rather than have a single paper listing multiple cultivars (for example see Morey, 1962) and to have registration articles under its own table of contents heading (for examples see Crop Science 1962 6(2) and Crop Science 2000 10(5)). However, even with these attempts inconsistencies continued to add to the difficulty of researching registered materials.

It was clear some mechanism to search registered materials was needed due to the difficulty of finding registration articles in the various journals and searching these articles by crop, trait, category, or other groupings. In response to the CSSA recommendation to publish an alphabetical list of registered cultivars, a list was distributed entitled Registered Field Crop Cultivars covering all cultivars through the end of 1964 (Annual Meeting, 1966). This list consisted of a mimeographed report distributed by the USDA and CSSA. This list was updated in the 1982 CSSA publication Registered Field Crop Cultivars: 1926-1981 (Miller and Brown, 1982). Although a great improvement, these publications fall short in that they are not electronically searchable and 
they only list and reference registered cultivars. Thus there was still no listing of the other registered genetic materials (germplasm and parental lines). Hence, Registered Field Crop Cultivars: 1926-1981 only covered two-thirds of the material registered before 1982 .

In 1999, the USDA-ARS GRIN started listing Registered plant materials and currently provides a searchable, electronic vehicle for researching accessions in the National Plant Germplasm System (http://www.ars-grin.gov/npgs/ searchgrin.html). Also available through GRIN is a cropspecific searchable portion of the database devoted specifically to Crop Science Registration (http://www.ars-grin.gov/ cgi-bin/npgs/html/csrlist.pl). This greatly facilities crop-specific searches of Registered materials by allowing searches by crop, registration category (cultivar, germplasm, genetic stocks, or parental lines), variety name, recent registration articles or by key words from the Crop Science descriptors. In addition to GRIN, the new format of plant registration articles in Journal of Plant Registrations and the yearly summaries of materials, further aids in finding and researching registered materials. Both GRIN and the yearly summaries facilitate searches of registered materials enabling researchers to find the papers for more detailed information.

The very nature of the evolution of Crop Registration articles has contributed to the appearance of a piecemeal system for their publication. For example, the pearl millet [Pennisetum glaucum (L.) R. Br.] cultivar Starr was first registered in 1953 (Hein 1953) with the registration number CV-1 under the Other Grasses crop category. This was followed by the registration of five other pearl millet cultivars (GAHI 1 [CV-6], Triflate [CV-25], GAHI 3 [CV-40], Trileaf 1 [CV-50], and WC-C75 [CV-95) under the Other Grasses crop category. Between the registration of WC-C75 in 1985 (Andrews et al., 1985) and the registration of Tifleaf in 1988 (Hanna et al., 1988), pearl millet stopped being listed under the crop category other grasses and started being listed under its own crop category of millet, pearl. This means several things when searching registration articles for pearl millet:

- If searching GRIN under the crop Millet, Pearl, the cultivars GAHI 1, Triflate, GAHI 3, Trileaf 1, and WC-C75 are not listed as they are under Other Grasses;

- If searching GRIN under the genus Pennisetum, one will find two Pennisetum glaucum cultivars with registration numbers CV-1 and CV-6.

Other species listed in multiple categories include:

- Agropyron hybrid-Wheatgrass and Other Grasses

- Agrostis stolonifera L.-Bentgrass and Other Grasses

- Bouteloua curtipendula (Michx.) Torr.-Grama Grasses and Other Grasses

- Cynodon dactylon var. dactylon-Bermudagrass and Other Grasses

- Dactylis glomerata L.-Orchardgrass and Other Grasses
- Festuca arundinaceae Schreb.-Fescue and Other Grasses - Lens culinaris subsp. cuinaris-Lentil and Other Legumes

- Lotus corniculatus L. and L. tenuis Waldst \& Kit. ex Willd.-Trefoil, Birdsfoot and Other Legumes

- Melilotus albus Medik. and M. officinalis (L.) Lam.Sweetclover and Other Legumes

- Phleum pratense L.-Timothy and Other Grasses

- Pisum sativum L.-Pea and Other Legumes

- Sorghum bicolor subsp. bicolor-Sorghum, Broomcorn, and Sudangrass

- Thinopyrum intermedium (Host) Barkworth \& D.R. Dewey-Wheatgrass and Other Grasses

- Trifolium incarnatum L.-Clover, Crimson and Other Legumes

- Trifolium pratense L.-Clover, Red and Other Legumes

- Trifolium repens L.-Clover, White and Other Legumes

Lastly, registration numbers in each category are supposed to be assigned to registered materials sequentially. Unfortunately, there are cases of missing registration numbers. The crop category Clover, Red is a good example as registration numbers CV-7 to CV-15 are completely missing due likely to a mix-up with the crop Other Legumes category (G. Pederson, personal communication, 2009). In November 1993, instead of going to the next sequential Clover, Red CV number, CV-7, Red Clover cultivar Arlington (Smith et al., 1973) was assigned CV-16, which was the next sequential Other Legumes CV number. Smith et al. (1973) was immediately followed by the registration of another red clover cultivar, Kenstar, as CV-17 (Norman and Anderson, 1973). Rather than go back and renumber these cultivars, it was likely deemed better to continue and in this case not to worry about the missing red clover CV numbers.

\section{Trends in Crop Registrations}

During the pre-Crop Science period (1926-1961) while the number of registration articles remained relatively constant with less than 20 registration articles a year, the number of registered accessions (cultivars only during this period) showed three noticeable peaks in the number of accessions registered in 1926, 1936, and 1958 (Fig. 1). These peaks corresponded for the most part to the first-time registration of standard cultivars of particular crops: the initial registration of 299 standard cultivars of wheat and 42 standard cultivars of oat in 1926; the initial registration of 31 standard cultivars of cotton (Gossypium hirsutum L.), 73 standard cultivars of sorghum [Sorghum bicolor (L.) Moench] and 35 newly listed standard cultivars of wheat in 1936; and the first registrations of both rice (Oryza sativa L.) and tobacco in 1958, as well as high numbers of new wheat, oat, and barley cultivars.

The post-Crop Science period (1962-2008) is characterized by an increase in both registration articles and registered materials for the first two decades (Fig. 1), followed by a leveling off of both the number of articles and genetic 


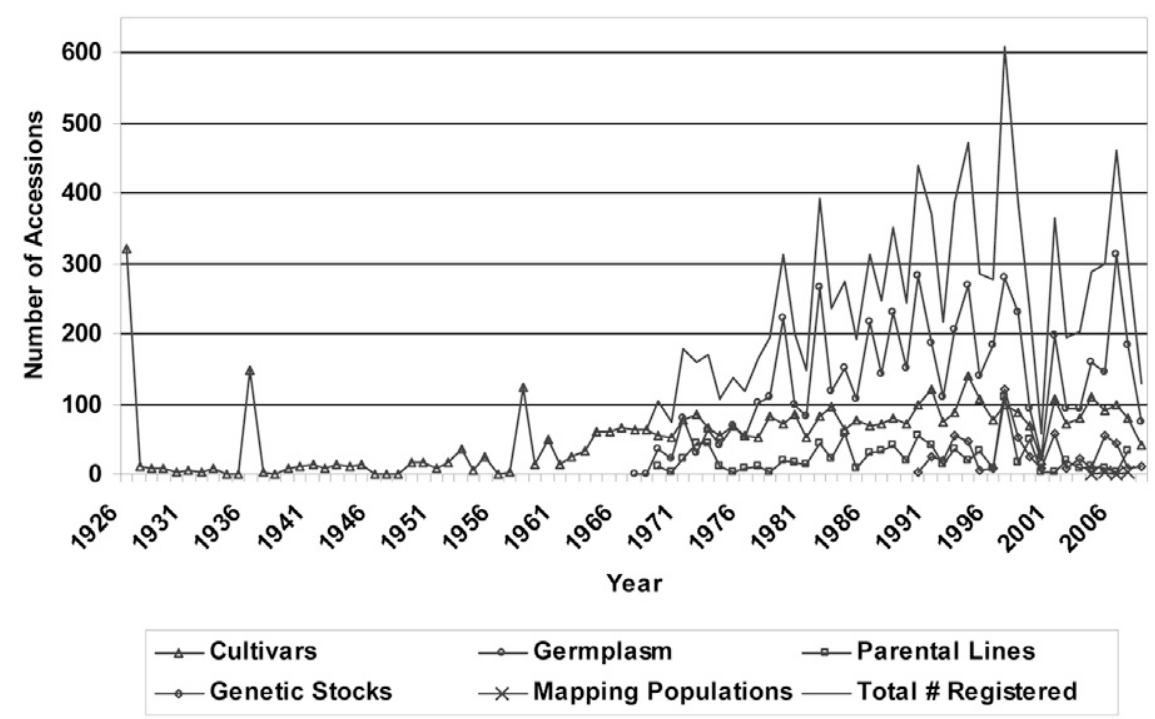

Fig. 1. The number of genetic materials accessions registered per year by category.

materials registered (Fig. 2). Interestingly, this increase in registered materials in the first two post-Crop Science decades is due not to the increased registration of cultivars, which on an average yearly basis per decade remained relatively constant, but due to the increased registration of other categories of materials primarily germplasm. There are two noticeable deviations in this post-Crop Science period evident in Fig. 1, a large decline in registered plant materials in 2000 and 2008.

The number of germplasm accessions registered per year has surpassed all other categories of registered germplasm since 1977 (Fig. 1). On an annual basis, the number of registered parental lines and genetic stocks were lower than the number of cultivars registered in every year since these categories were established, with the exception of 1997 (Fig. 1). Finally although the registration of mapping populations were only initiated in 2004 and only six mapping populations have been registered through the end of 2008, the registration of mapping populations represents a significant recognition of the value and future importance of such germplasm.

The majority $(86 \%)$ of registered genetic materials were submitted, and presumably developed, by breeders and researchers in the United States. The $14 \%$ of registered genetic materials which were developed outside the United States has been strong and constant as evidenced by the fact that in 1926, the first year of crop registration, genetic materials registered came from 27 different countries. There remains today a solid encouragement for registrations of genetic materials developed outside the United States.

\section{Benefits of Crop Registration}

The original intent for the registration of crop cultivars and the accompanying registration articles was for the dissemination of information, including identity, heritage, and characteristics of improved cultivars so that breeders, researchers, agronomists, and the public could access this information for improving crop yield and developing new crop cultivars. To show improvement, industry standards for each crop had to be established which provided a unified base to judge improvements. While information on characteristics of some early registration materials was often scant and lacked detail, the articles did provide comparative information on individual characteristics at multiple locations.

The publication of registration articles also provides a means to recognize the efforts and successes of plant breeders and germplasm developers, the role of parental lines and most recently, the importance of unique and characterized mapping populations in the development of commercial cultivars. Since the inception of crop registrations, the developers (authors) were awarded, in addition to the publication, a certificate from the Society recognizing the registered material.

Perhaps the most important element of crop registration is the requirement for the deposition of a voucher sample of the registered material with the NPGS for future public distribution. As previously mentioned, the requirement for a voucher specimen of "not less than six heads and one ounce of seed" to be deposited with the Bureau of Plant Industry was included in the first guidelines for crop registration in 1923 (Agronomic Affairs, 1923). While maintenance and distribution of the registered crop was not envisioned as a government function in the early days of crop registration, the establishment of the Regional Plant Introduction Stations in 1949 allowed a mechanism for maintenance and public distribution of registered materials.

The public distribution of registered materials is the responsibility of the author under standard Crop Registration guidelines for the first $5 \mathrm{yr}$ postpublication. After this initial $5 \mathrm{yr}$ period, the NPGS assumes the responsibility for maintenance and public distribution of registered materials. Exceptions to this standard 5-yr distribution guideline include: 


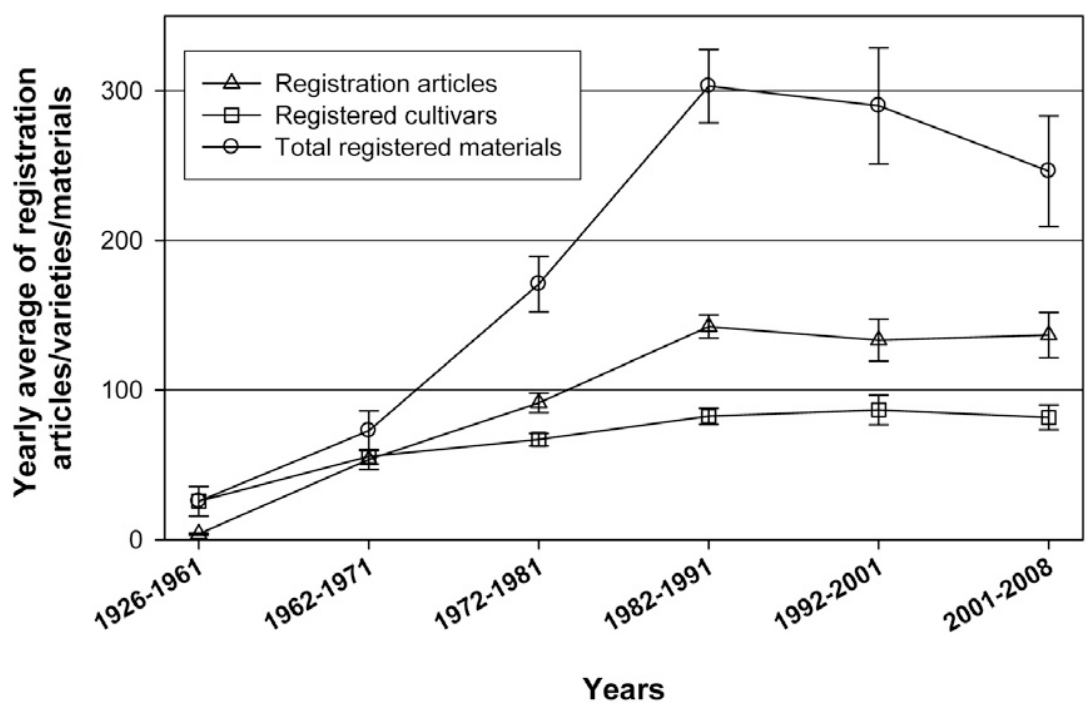

Fig. 2. Yearly average of registration articles, registered cultivars, and total registered materials per time period ( \pm SE).

- Genetic materials registered by international authors, where the NPGS requests permission from the author for immediate distribution rights after publication to facilitate release, distribution, and use of the registered materials;

- The author requests that the NPGS assumes distribution responsibility during the initial 5-yr period;

- The author requests and assumes distribution responsibility of the registered material for some period of time up to $20 \mathrm{yr}$ (see Intellectual Property Rights section below);

- Registered material is a crop not in the NPGS and the author is from a CGIAR genebank. In this case, the CGIAR genebank would assume the responsibility for maintenance and public distribution of the registered material.

\section{Intellectual Property Rights and Registered Materials}

While the registration of genetic materials by itself offers no legal or proprietary protection to our knowledge, it does provide a means to publically disclose and describe cultivars. Further, there are no restrictions to registering genetic materials which have previously been protected by patenting, Plant Variety Protection or some other Intellectual Property Rights (IPR).

Before 2004, genetic materials with intellectual property protection prohibiting immediate public distribution for use in breeding and research were not generally accepted for registration by the Crop Science Society of America (CSSA). The guidelines were clear that the intent was for registered material to be publically available. The National Center for Genetic Resources Preservation (NCGRP), a USDA-ARS facility, has the responsibility for safekeeping and ensuring that both Crop Registration and Plant Variety Protection (PVP) voucher samples are publically available through the NPGS after expiration (PVP samples) or author distribution (Crop Registration samples). Due to this dual role, and the fact that PVP covers the variety (not just the voucher sample) the NCGRP was caught in a dilemma regarding public distribution of samples which were known to be covered by PVP. In 2004 CSSA C852 Committee on Crop Registration expanded the availability of CSSA registration to include genetic materials covered by various IPR instruments including patents and Material Transfer Agreements. Under this expanded policy for CSSA registration, the genetic material must be available under some terms during the period of protection, and authors (or their institutions) assume the responsibility for distribution until expiry of protection which cannot exceed $20 \mathrm{yr}$. After expiry of protection or $20 \mathrm{yr}$ (whichever comes first), the material is available for unrestricted public distribution through the NPGS. For the most current information on this evolving topic, see Instructions to Authors for the Journal of Plant Registrations at https://www.crops.org/sites/default/files/file_uploads/ JPR\%20Instruction\%20to\%20Authors\%202009.pdf.

The most recent modification of policy regarding CSSA registration of genetic materials is a result of the International Treaty on Plant Genetic Resources for Food and Agriculture (2008) (IT) which established a standard international mechanism, including a Standard Material Transfer Agreement (SMTA), for exchanging plant genetic resources for a selected group of crops (Annex 1 crops). Genebanks in the CGIAR and other international genebanks are now including the Standard Material Transfer Agreement (SMTA) from the IT with distributions of all their crop genetic resources, whether Annex 1 crops or not.

Because breeders and researchers from these genebanks, as well as from nations which are party to the IT, could be obligated to apply the SMTA to distributions of all registered plant genetic materials, the CSSA C582 
Committee on Crop Registration and the NPGS have responded quickly to this new requirement by developing a system to register and distribute genetic materials covered by the SMTA. When a breeder in an IT party nation, or CGIAR center, wishes to apply for crop registration for material covered under the IT, they must include a copy of the SMTA or a notice with the voucher specimen that the material is covered by the SMTA. The NPGS will in turn distribute these materials to all requestors accompanied by the SMTA, and notify the IT Governing Body of that distribution. This provides a mechanism for researchers and breeders in nations that are parties to the IT, as well as CGIAR centers, to register materials and deposit them with the NPGS as per CSSA Registration Guidelines.

\section{Safeguarding and Releasing Voucher Specimens}

The NCGRP is responsible for obtaining a good quality seed specimen, accompanied by a completed Storage Information Form for all registered materials before publication (http://www.ars-grin.gov/ncgrp/forms/SIF705.doc). Seed samples are received by NCGRP, entered into GRIN, assigned a PI number, equilibrated to 6 to $10 \%$ moisture content, germination tested and if of acceptable quality ( $>85 \%$ germination in most cases), the seed is heat sealed in an aluminum bag seed storage bag, labeled, and stored at $-20^{\circ} \mathrm{C}$. Typically a seed specimen for registration consists of 7500 clean seed for open-pollinated cultivars and germplasm, 5000 clean seed for self-pollinated species, 500 clean seed for each line of a mapping population and 100 to 1000 clean seed for genetic stocks. If the seed number is low or the seed is not of acceptable quality, the author may be contacted to supply additional seed or a new sample. When a replacement sample is requested, the author can elect to have the original sample either returned or destroyed on quality verification of the replacement sample. If the seed is difficult to regenerate, as in the case of mapping populations or genetic stocks, the NCGRP will work with the author and the appropriate NPGS crop curator to develop an acceptable solution. After $5 \mathrm{yr}$, or after the period of restricted distribution, the voucher seed sample is typically equally divided with one-half remaining in long-term storage at NCGRP and the other half being sent to the appropriate NPGS field station for regeneration and public distribution under NPGS policies.

Authors from outside the United States who wish to register materials need to contact the NCGRP to obtain an import permit before shipping the voucher specimen. The NCGRP will electronically transmit an import permit and import labels for the specimen. Note that import labels are now individually numbered and hence each shipment requires its own import label. The author is responsible for obtaining the necessary phytosanitary and export permits as required. If the crop/specimen is subject to U.S. quarantine regulations, the NCGRP will work with the NPGS crop curator to have the material grown-out in a quarantined facility before public release by the NPGS. As mentioned earlier, the NCGRP will also ask foreign authors for permission for immediate release into the NPGS to facilitate distribution of the material rather than waiting the conventional 5-yr period for author distribution.

Although uncommon, the NPGS will accommodate to the best of their ability voucher specimens from registered vegetatively-propagated material. When the crop is not a species maintained by the NPGS, the NCGRP will strive to find another recognized international genebank which can provide secure long-term maintenance and distribution of the sample.

\section{National Plant Germplasm System Distribution of Registered Materials}

An important rationale for the registration of genetic materials is to get information on new genetic materials into the public domain to encourage their use by breeders and researchers. Therefore, distribution of registered genetic materials is an indicator of interest in, and use of, registered materials. Distribution records for registered materials through the NPGS are available through GRIN since 1982 yet these records only include NPGS distributed material and not material distributed by the authors during the first $5 \mathrm{yr}$ or in subsequent years. Author distributions are significant (J. Pedersen, personal communication, 2009) and therefore the distribution data following is an underestimation of the use of the registered genetic materials.

In the $26 \mathrm{yr}$ period since 1982, 103,771 registered materials were distributed by the NPGS ( 4000 distributions/year). The vast majority of the registered material was distributed to breeders and researchers in North America (96\%), with 84\% distributed within the United States, $10 \%$ to Canada, and 2\% to Mexico (Fig. 3) with Canada and Mexico making up $74 \%$ of the non-U.S. distributions. Africa accounted for $10 \%$ of the non-U.S. distribution followed by Europe (5\%), Central and South America (3\%), India (3\%), Asia (3\%), and Australia (2\%) (Fig. 4). In 2008, registered genetic materials made up 8\% of the total accessions distributed by the NPGS.

Separating the distribution of registered material by decade (1982-1989, 1990-1999, 2000-2008), it is interesting that 7 of the top 10 crop species distributed remained the same for all three decades (Wheat, Oat, Barley, Rice, Maize, Sunflower, Tobacco, and Cotton). Of the other crops which were among the top 10 distributed in one or more of the decades (Soybean, Alfalfa, Sorghum, Pea and Peanut) only peanut was not in the top 15 crops distributed in all three decades (Peanut was number 17th in 1982-1989). The multi-species categories Other Legumes and Other Grasses were also in the top 15 crop categories distributed in all three decades. Cereals and legumes were also noted 


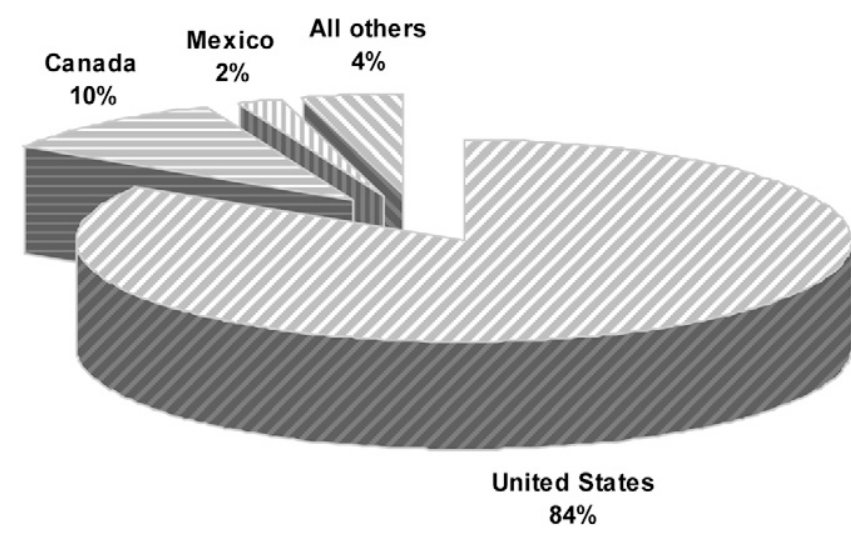

Fig. 3. Country of distribution of registered genetic materials by the National Plant Germplasm System 1982-2008.

as the first and third most used crops in a study analyzing plant genetic resources used in published papers from four plant breeding journals (Dudnik et al., 2001).

In the period 1982-2008, 9152 individual accessions from registered materials were distributed by the NPGS (average of 352 registered accessions/year). The most requested registered accessions were two maize parental lines, B73 (PI 550473, 733 requests) and Mo17 (PI 558532, 532 requests) registered in 1972 (Russell, 1972) and 1973 (Zuber, 1973), respectively. Germplasm made up the largest group of registered materials distributed with 4285 Germplasm accessions distributed from 1982 to 2008. Distributions of the other registration categories were 3790 Cultivar accessions, 768 Parental Lines accessions, and 306 Genetic Stocks.

Confirming the long-lasting importance of registered materials, in the past $26 \mathrm{yr}, 265$ of the original cultivars registered in 1926 were distributed. These include:

- The three improved barley cultivars registered in 1926

(Harlan et al., 1926) have been distributed a total of 52 times over the past $26 \mathrm{yr}$;

- 63 of the 64 oat cultivars registered in 1926 (Stanton et al., 1926) have been distributed a total of 581 times in the past $26 \mathrm{yr}$.

- 199 of the 252 wheat cultivars registered in 1926 (Clark et al. (1926a), and Clark et al., 1926b) were distributed a total of 3400 times with one standard accession (PI 10474) being distributed 93 times and one improved variety (CV 240 'Hope') being distributed 65 times (an average of 3.5 and 2.5 times, respectively per year for the past $26 \mathrm{yr}$ !). Of the 23 improved wheat varieties registered in 1926, 22 varieties were distributed 316 times in the past $26 \mathrm{yr}$;

- One standard wheat accession (PI 10474), from the original 1926 registered cultivars is among the top 100 crop science accessions most frequently distributed in the past $26 \mathrm{yr}$.

Lasting importance of registered cultivars is also confirmed by the fact that $84 \%$ of those accessions registered more than 50 yr ago (1926-1958) have been requested and

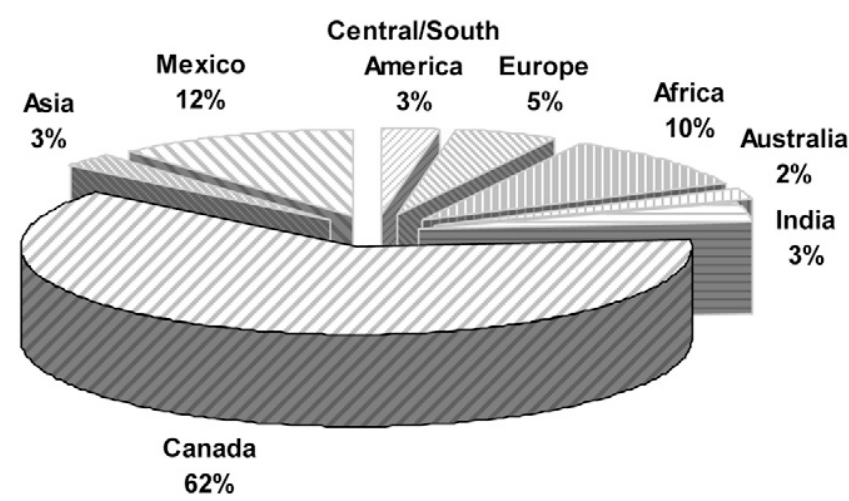

Fig. 4. Non-U.S. distribution of registered genetic materials by the National Plant Germplasm System 1982-2008.

distributed in the past $26 \mathrm{yr}$ (713 accessions distributed out of 849 accessions registered). These accessions represent $12 \%$ of the total Crop Registration accessions distributed in the past $26 \mathrm{yr}$.

\section{SUMMARY}

The CSSA registration of plant genetic materials has a long history of positive impact on the development, information exchange, and use of new and novel genetic materials. The strong collaborative relationship with USDA-ARSNPGS has greatly facilitated this impact. The intent of the registration of plant genetic materials, to document, development and encourage distribution, and use of new genetic materials, has remained relatively constant over the past $80 \mathrm{yr}$. As science, IPR and the exchange of international germplasm continue to evolve; the registration of genetic materials will need to continue to evolve to meet these growing needs. The fact that distribution by the NPGS, which does not include distribution of materials by the authors, has remained high and strong even with material registered decades in the past, clearly demonstrates the impact and role registration materials have had on continued food safety and crop productivity.

\section{Acknowledgments}

The authors thank all the breeders and researchers who have registered crop genetic materials over the past $80 \mathrm{yr}$. The authors also thank Drs. Peter Bretting and Gary Pederson for helpful comments and suggestions in the manuscript.

\section{References}

Agronomic Affairs. 1922. Minutes of the annual meeting: Report of the Committee of Varietal Standardization. J. Am. Soc. Agron. 14(9):360-363.

Agronomic Affairs. 1923. Minutes of the annual meeting: Report of the Committee on Methods of Registration of Wheat, Oats and Barley. J. Am. Soc. Agron. 15(12):527-529.

Agronomic Affairs. 1924a. Committees on registration of varieties of wheat, oats and barley. J. Am. Soc. Agron. 16(4):NP

Agronomic Affairs. 1924b. Minutes of the annual meeting: Report of the Varietal Standardization Committee. J. Am. Soc. 
Agron. 16(12):803.

Agronomic Affairs. 1925. Minutes of the eighteenth annual meeting: Report of the Committee on Varietal Standardization. J. Am. Soc. Agron. 17(12):825-826.

Agronomic Affairs. 1926a. Minutes of the nineteenth annual meeting: Report of Committee of Varietal Standardization. J. Am. Soc. Agron. 18(12):1144-1145.

Agronomic Affairs. 1926b. Minutes of the nineteenth annual meeting: Report of the Sub-committee on Barley Registrations. J. Am. Soc. Agron. 18(12):1145.

Agronomic Affairs. 1927. Minutes of the twentieth annual meeting: Sub-committee Report on Corn Registration. J. Am. Soc. Agron. 19(12):1129-1130.

Agronomic Affairs. 1928a. Sub-committee on soybean registration. J. Am. Soc. Agron. 20(4):416.

Agronomic Affairs. 1928b. Minutes of the twenty-first annual meeting: Report of Committee of Varietal Standardization. J. Am. Soc. Agron. 20(12):1353-1354.

Agronomic Affairs. 1929. Minutes of the twenty-second annual meeting: Sub-committee report on the registration of corn varieties. J. Am. Soc. Agron. 21(12):1196-1198.

Agronomic Affairs. 1931. Minutes of the twenty-fourth annual meeting: Varietal Standardization and Registration Committee Report. J. Am. Soc. Agron. 23(12):1023-1027.

Agronomic Affairs. 1932. Minutes of the twenty-fifth annual meeting: Report from Committee on Varietal Standardization and Registration Report. J. Am. Soc. Agron. 23(12):1023-1027.

Agronomic Affairs. 1934. Minutes of the twenty-seventh annual meeting of the society: Report on the Committee of Varietal Standardization and Registration. J. Am. Soc. Agron. 26(12):1043.

Agronomic Affairs. 1936. Minutes of the twenty-ninth annual meeting of the society: Varietal Standardization and Registration Committee Report. J. Am. Soc. Agron. 28(12):1027-1028.

Andrews, D.J., S.C. Gupta, and P. Singh. 1985. Registration of WC-C75 pearl millet. Crop Sci. 25:199-200.

Annual Meeting. 1953. Minutes from the forty-fifth annual meeting of the American Society of Agronomy: Committee for Varietal Standardization and Registration. Agron. J. 45(12):650.

Annual Meeting. 1956. Minutes from the forty-eighth annual meeting of the American Society of Agronomy: Report from the Committee on Varietal Standardization and Registration. Agron. J. 48(12):607-608.

Annual Meeting. 1964. Minutes from the fifty-fifth annual meeting, American Society of Agronomy Report: Report from the Committee on Cooperation with Seed Interests. Crop Sci. 4(1):122-123.

Annual Meeting. 1966. Minutes from the annual meeting, Crop Science Society of America: Report from the Committee on Varietal Standardization and Registration. Crop Sci. 6(1):103.

Badu-Apraku, B., S. Twumasi-Afriyie, P.Y.K. Sallah, W. Haag, E. Asiedu, K.A. Marfo, S. Dapaah, and B.D. Dzah. 2006. Registration of 'Obatanpa GH' maize. Crop Sci. 2006 46: 1393-1395.

Brown, H.B. 1936. Cotton varieties recognized as standard commercial varieties. J. Am. Soc. Agron. 28(1):69-79.

Button, G.W. 1969. Registration of pearl millet inbreds Tift 23B , $_{1}$ Tift 23A $\mathrm{A}_{1}$, Tift $23 \mathrm{DB}_{1}$, and Tift 23DA 1 (Reg. Nos. PL 1, PL 2, PL 3, and PL 4). Crop Sci. 9:397.

Clark, A.J., H.H. Love, and E.F. Graines. 1926a. Registration of standard wheat varieties. J. Am. Soc. Agron. 18(10):920-922.

Clark, A.J., H.H. Love, and J.H. Parket. 1926b. Registration of improved wheat varieties. J. Am. Soc. Agron. 18(10):923-935.

Dudnik, N.S., I. Thormann, and T. Hodgkin. 2001. The extent of use of Plant Genetic Resources in research-A literature survey. Crop Sci. 41:6-10.

Graber, L.F. 1956. Registration of varieties and strains of alfalfa. Agron. J. 48(12):587-588.

Gritton, E.T., and D.J. Hagedorn. 1971. Registration of Wisconsin pea cultivars (Reg. Nos. 2 to 6). Crop Sci. 11(6):941.

Hanna, W.W., H.D. Wells, G.W. Burton, G.M. Hill, and W.G. Monson. 1988. Registration of 'Tifleaf 2' pearl millet. Crop Sci. 128:1023.

Hanway, D.G. 1985. History of Crop Science. Crop Sci. 25(2):206-208.

Harlan, H.V., E.F. Gaines, and R.G. Wiggans. 1926. Registration of barley varieties. J. Am. Soc. Agron. 18(10):947-948.

Hein, M.A. 1953. Registration of varieties and strains of pearl millet (Pennisetum glaucum (L.) R. Br.). Agron. J. 45(11):573.

Hussain, T., P. Tausend, G. Graham, and J. Ho. 2007. Registration of IBM2 SYN10 doubled haploid mapping population of maize. J. Plant Reg. 1:81.

International Treaty for Plant Genetic Resources for Food and Agriculture. 2008. www.planttreaty.org (verified 31 Mar. 2010). FAO, Rome, Italy.

Jensen, N.F. 1966. Registration of Orbit oats (Reg. No. 203). Crop Sci. 6(5):501-502.

Johnson, I.J. 1985. Crop Science- The birth of a new technical journal. Crop Sci. 25(2):205.

Johnson, I.J. and H.I. Hamilton. 1961. Editorial- The new CROP SCIENCE Journal. Crop Sci 61(1):NP.

Morey, D.D. 1962. Registration of AB-110 oats(Reg. No. 173). Crop Sci. 2(12):531.

Morse, W.J. 1943. Soybean variety registered, I ${ }^{1}$. J. Am. Soc. Agron. 35(9):843-844.

Miller, P.A., and W.L. Brown. 1982. Registered Field Crop Varieties: 1926-1981. Spec. Publ. CSSA, Madison, WI.

Narvel, J.M., T.E. Carter, Jr., L.R. Jakkula, J. Alvernaz, M.A. Bailey, M.A.R. Mian, S.H. Lee, G.J. Lee, and H.R. Boerma. 2004. Registration of NC113 soybean mapping population. Crop Sci. 44:704-706.

Norman, L.T., and M.K. Anderson. 1973. Registration of Kenstar red clover (Reg. No. 17). Crop Sci. 13(6):772.

Oakley, R.A. 1920. Report of Committee of Varietal Standardization. J. Am. Soc. Agron. 12(8-9):234-235.

Palmer, R.G., and H. Skorupska. 1990. Registration of a Male-Sterile Genetic Stock (T295H) of Soybean. Crop Sci. 130(1):244.

Parker, J.H. 1938. Registration of improved sorghum varieties. I. J. Am. Soc. Agron. 30(4):306-308.

Pedersen, J. 2007. Editorial. J. Plant Reg. 1:iv.

Russell, W.A. 1972. Registration of B70 and B73 parental lines of maize. Crop Sci. 12:721.

Smith, R.R., D.P. Maxwell, E.W. Hanson, and W.K. Smith. 1973. Registration of Arlington red clover (Reg. No. 16). Crop Sci. 13(6):771.

Stanton, T.R., F. Griffee, and W.C. Etheridge. 1926. Registration of varieties and strains of oats. J. Am. Soc. Agron. 18(10):935-947.

Suneson, C.A. 1969. Registration of barley composite crosses (Reg. Nos. GP 1 to 9, inclusive). Crop Sci. 9(3):395-396.

Zuber, M.S. 1973. Registration of 20 maize parent lines. Crop Sci. 13: 779-780. 